\title{
Petawatt Laser Data Analysis and Technology Development
}

\author{
M.H. Key, M.D. Perry
}

August 30, 2000

U.S. Department of Energy

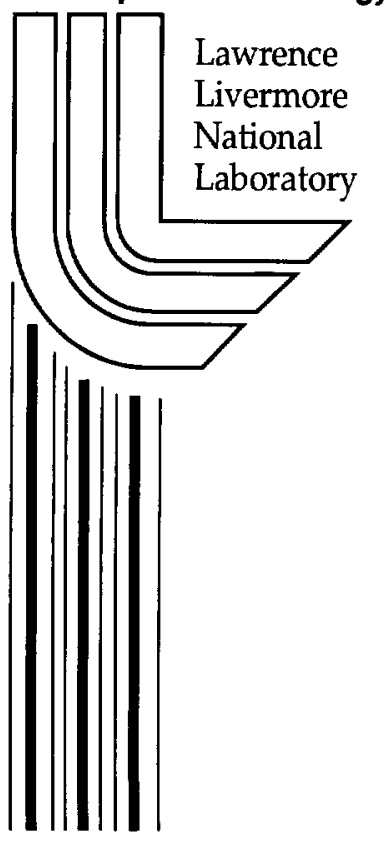




\section{DISCLAIMER}

This document was prepared as an account of work sponsored by an agency of the United States Government. Neither the United States Government nor the University of California nor any of their employees, makes any warranty, express or implied, or assumes any legal liability or responsibility for the accuracy, completeness, or usefulness of any information, apparatus, product, or process disclosed, or represents that its use would not infringe privately owned rights. Reference herein to any specific commercial product, process, or service by trade name, trademark, manufacturer, or otherwise, does not necessarily constitute or imply its endorsement, recommendation, or favoring by the United States Government or the University of California. The views and opinions of authors expressed herein do not necessarily state or reflect those of the United States Government or the University of California, and shall not be used for advertising or product endorsement purposes.

This work was performed under the auspices of the U. S. Department of Energy by the University of California, Lawrence Livermore National Laboratory under Contract No. W-7405-Eng-48.

This report has been reproduced directly from the best available copy.

Available electronically at http://www.doe.gov/bridge

Available for a processing fee to U.S. Department of Energy

and its contractors in paper from

U.S. Department of Energy

Office of Scientific and Technical Information

P.O. Box 62

Oak Ridge, TN 37831-0062

Telephone: (865) 576-8401

Facsimile: (865) 576-5728

E-mail: reports@adonis.osti.gov

Available for the sale to the public from

U.S. Department of Commerce

National Technical Information Service

5285 Port Royal Road

Springfield, VA 22161

Telephone: (800) 553-6847

Facsimile: (703) 605-6900

E-mail: orders@ntis.fedworld.gov

Online ordering: http:/www.ntis.gov/ordering.htm

OR

Lawrence Livermore National Laboratory

Technical Information Department's Digital Library

http://www.llnl.gov/tid/Library.html 


\title{
Final Report
}

LDRD 98-ERD-07 (June 1 to Oct. 1 1999)

\section{Petawatt Laser Data Analysis and Technology Development}

\author{
M. H. Key (PI) \\ M. D. Perry (co- PI)
}

\section{Introduction}

The Petawatt (PW) laser beam line at the LLNL Nova laser facility was unique in the world in supplying an order of magnitude higher power (1PW in pulses of $500 \mathrm{fs}$ duration) than lasers elsewhere. Focussed to intensities reaching $3 \times 10^{20} \mathrm{Wcm}^{-2}$, it opened up a new regime of experimental science where free electron energies in the light wave are strongly relativistic. After full operational capability of the PW beam-line was reached, close to $25 \%$ of the operation of the Nova facility was dedicated to PW shots for two years, prior to the shut down of Nova in May 1999. A wealth of novel scientific data was obtained and it motivated the primary objective of this June 1 to Oct. 1,1999 LDRD, which was to complete systematic analysis of the PW laser data. This was done by the team, which had conducted the experiments working with associated experts in theoretical modeling of the complex physical phenomena. A second objective was to develop a key new technology of large area transmission gratings needed for the next step to higher energy PW laser development. This work was done by the team, which developed the reflective grating technology.

\section{Scientific importance and spin off}

The scientific results obtained with the PW laser had considerable impact and led to numerous presentations including keynote, plenary and invited talks at international conferences (see list V1 to V8 and appended copies), technical reports and publications (see list P1 to P21 and appended copies). There was significant public relations value, the results being featured, for example, on the scientific highlights web site at the 1999 APS DOP meeting and in the LLNL Science and Technology Review ${ }^{[\mathrm{P} 20]}$. A record of invention was filed for a novel ion beam source for which a patent application is in progress. Future exploitation of the science was assured by the creation of a new 4 year multi - institution collaborative research program in "exploration of fast ignition", supported by the DOE office of fusion energy sciences. The technical R\&D on 
transmission grating development was at the forefront of diffraction grating technology and is a key enabling technology for future higher energy PW lasers.

\section{Analysis of experiments}

Analysis of the PW data has yielded outstandingly interesting scientific results, which can be summarized under the headings of:

- Intense collimated high-energy proton beams

- Relativistic electrons, multi Mev photons and photo-nuclear and pair production phenomena

- Fast ignition

\subsection{Intense collimated high energy proton beams}

One of the most interesting discoveries was the least expected. In studies aimed at characterizing the source characteristics of relativistic electrons generated by irradiating solid targets in vacuum, it was observed that an intense highly collimated beam of protons with energies up to $55 \mathrm{MeV}$ was emitted perpendicular to the rear surface of the target ${ }^{\{\mathrm{P}, \mathrm{P} 4, \mathrm{P} 16\}}$. This was first seen as a sharply defined beam in an image recorded by radiochromic film (which changes color in proportion to the dose of ionizing particles or radiation). Quantitative analysis demonstrated that as much as $7 \%$ of the laser energy was converted to $>20 \mathrm{MeV}$ protons ${ }^{|\mathrm{P}| 6 \mid}$. A magnetic deflection spectrometer showed a sharp cut off in the energy spectrum, which was at up to $55 \mathrm{MeV}$ on axis, and at lower energies for more off axis angles. The emittance of the beam was comparable to that used in proton accelerators. Nuclear activation through the $(\mathrm{p}, \mathrm{n})$ process in Ti gave confirmation of the angular pattern of the proton beam by autoradiography and confirmed the estimated conversion efficiency. The acceleration mechanism was identified and modeled analytically ${ }^{\mid \mathrm{P} 4\rfloor}$ and numerically ${ }^{[\mathrm{P} 21]}$. It is due to a sudden formation by relativistic electrons of a Debye sheath at the solid vacuum interface creating accelerating fields for ions leaving the target of many $\mathrm{MeV}$ per micron. The ion beam has significant applications potential, which is now being explored and a record of invention has been filed.

\subsection{Relativistic electrons, multi Mev photons and photo -nuclear and pair production phenomena}

The relativistic electron source with energies up to $100 \mathrm{MeV}^{[\mathrm{P3}]}$ and typically 4 $\mathrm{MeV}$ "temperature" enables generation of an intense continuum of multi MeV x-ray 
photons through the process of Bremsstrahlung. Gold targets $1 \mathrm{~mm}$ thick emitted $\mathrm{x}$-rays in a broad $100^{\circ}$ forward cone angle in the direction of the laser. Conversion to $\mathrm{MeV}$ photons was $3 \%$ (implying $>40 \%$ conversion to relativistic electrons) and dose levels as high as 2 rads at $1 \mathrm{~m}$ were recorded ${ }^{[\mathrm{P} 6 \mathrm{P} 4 \mid}$. Radiographs of sub $\mathrm{mm}$ resolution were obtained via as much as $15 \mathrm{~cm}$ of $\mathrm{Pb}$. The application to dynamic radiography in the stockpile stewardship program requires even higher source intensities, which would be obtained if the cone angle of the source could be narrowed, which is an area of ongoing investigation.

Scientifically exciting byproducts of this work included the opening up of study of laser induced photonuclear processes ${ }^{|\mathrm{P} 2|}$. Photons at energies $>10 \mathrm{MeV}$ induce $(\mathrm{g}, \mathrm{xn})$ nuclear activation, which was observed in $\mathrm{Au}$ for $\mathrm{x}=1$ to 7 and used to measure the photon spectrum at energies up to $70 \mathrm{MeV}$ in addition to the angular pattern of emission ${ }^{[\mathrm{P} 13, \mathrm{P} 19]}$; photo dissociation of Uranium was similarly induced ${ }^{|\mathrm{P} 2|}$. The first observations of e+e- pair production with lasers were also achieved ${ }^{[\mathrm{P} 3 \mid}$ and the data suggested that, in addition to pair production through absorption of photons interacting with high $\mathrm{z}$ matter, there was evidence of electron collisional production of pairs, which opens the way to laboratory study of the astrophysically significant electron positron plasma.

\subsection{Fast Ignition}

The Fast Ignition (FI) Inertial Fusion Energy (IFE) Concept is recognized as having the potential to improve the attractiveness of IFE reactors. FI ignites precompressed fuel pellets with a separate laser pulse, achieving much higher gain than is otherwise feasible. This higher gain and other advantages in the target, driver and ignition system lead to a more attractive power plant ${ }^{[\mathrm{PS}, \mathrm{P} 17]}$.

The scientific basis for the ignition spark energy and the fusion gain is wellestablished, ${ }^{[P 5]}$ but there is significant uncertainty in the efficiency of energy transfer from the ignitor laser to the ignition spark. In the most developed scenario, the laser beam must penetrate sub-critical density plasma and create a directed beam of relativistic electrons, which carries the ignition energy to the ignition spark. The proton beam discovered in our work also created a novel possibility for fast ignition in which a beam of ballistically focused protons more easily penetrates the peripheral plasma and heats the ignition spark ${ }^{|\mathrm{P}| 4 \mid}$. There is uncertainty in the energy transfer physics in both these scenarios and the physics involved is complex and relatively unexplored.

The transport of energy from the laser beam into solid density material by relativistic electrons was studied in our experiments. The heating effect of the electrons in solid targets was measured in two ways. Evidence of temperatures in the range 0.5 to 
$1 \mathrm{keV}$ was obtained from observation of a narrow DD thermonuclear fusion peak superimposed on an intense broad background from $(\gamma, n)$ and $(p, n)$ processes, in neutron energy spectra ${ }^{|\mathrm{PS}|}$. Data were recorded from targets of $\mathrm{CD}_{2}$ with a front layer of $\mathrm{CH}$ or $\mathrm{Cu}$. Further evidence was obtained from x-ray spectra of emission from $\mathrm{Al}$ sensor layers buried up to $20 \mu \mathrm{m}$ deep in $\mathrm{CH}$ targets. Temperatures of about $300 \mathrm{eV}$ and density of 0.6 $\mathrm{g} / \mathrm{cc}$ were recorded ${ }^{[\mathrm{P} 8, \mathrm{P} 9]}$. Of particular interest, were pinhole camera images of the $\mathrm{X}$ rays from the $\mathrm{Al}$, which showed an annular pattern of heating with an $80 \mu \mathrm{m}$ diameter. Images from the rear side of targets having Al layers up to $100 \mu \mathrm{m}$ from the front surface showed a similar annulus. This data strongly suggest heating in a collimated pattern as predicted by recent theoretical modeling of magnetically guided energy flow. The high temperature and density at distances more than $10 \mathrm{x}$ the focal spot diameter has never been seen before and this work is, therefore, significant in the quest for fast ignition.

\section{Transmission grating development}

The development at LLNL of $1 \mathrm{~m}$ diameter reflective diffraction gratings used for pulse compression, was the key technology for the PW laser. The limiting factor on the laser power is damage to the gold coatings of the gratings.

The objective of this LDRD was to demonstrate fabrication of a large aperture fused silica grating used in transmission. Such transmission gratings operate without damage at much higher energy per unit area. Highlights of this work ${ }^{[\mathrm{P} 20]}$ and a detailed technical report ${ }^{[\mathrm{P}] \mid}$ are appended.

Computational modeling was used to define the required groove pattern for high efficiency operation in Littrow $m=-1$ order with $90^{\circ}$ deflection of the beam. The grating grooves have $0.75 \mu \mathrm{m}$ spacing and are very deep relative to their width. A test of the process at $5 \mathrm{~cm}$ aperture had earlier been shown to give $95 \%$ diffraction efficiency. A significant technology step addressed in this LDRD was the adaptation of the reactive ion beam etching (RIBE) process used in the grating manufacture to produce a $65 \mathrm{~cm}$ aperture grating on a fused silica substrate.

The grating fabrication process begins with coating the substrate with a resist. The resist is then exposed to a fringe pattern of the required spacing in the same large aperture laser interferometer that was used in manufacture of the reflection gratings. Chemical etching of the resist produces the required exposed pattern of bare fused silica and finally, the RIBE process is used to create the required groove depth in the fused silica before the residual resist is dissolved and washed off. 
The major technology goal is to obtain a spatially uniform etch rate in the RIBE process at large aperture. Modifications were made to a $30 \mathrm{~cm}$ aperture RIBE system and a rotating mask technique was developed to give $5 \%$ uniform etch rate (except in a small fraction of the area near the center). This was verified with test pieces placed at different radii.

During the 4 month period of this LDRD one $65 \mathrm{~cm}$ substrate was put through the full process. The RIBE etch depth measured in a small area near the edge was initially found to be too low and the grating was returned to the machine for further etching. Optical tests showed that in some areas high efficiency diffraction was obtained, but that overall the efficiency was lower and not spatially uniform. Tests showed that the additional etching had not increased the groove depth. This was attributed to a malfunction of the RIBE, due to incorrect gas feed during the etching process.

Despite this technical problem, significant progress was made towards large aperture transmission grating fabrication. In future work, the RIBE machine can be operated with improved gas feed control to rectify the problem. High diffraction efficiency over large aperture transmission gratings should then be achieved and should enable generation of up to $3 \mathrm{~kJ}$ laser pulse energies where the present $\mathrm{PW}$ laser limit is about $0.75 \mathrm{~kJ}$. Further work will be needed to develop methods to fabricate and mount gratings with thin $(<5 \mathrm{~mm})$ substrate thickness while maintaining adequate planarity.

This technology will be a key factor in any next generation high-energy PW laser.

\section{Acknowledgements}

This work was accomplished with the help of many colleagues whose names appear in the listed publications

\section{Papers}

P1. J. Britten, H. T. Nguyen, S. R. Bryan, M. D. Perry, "Fabrication of Efficient, Large Aperture Transmission Diffraction Gratings by Ion-Beam Etching," (UCRL---------)

P2. T. E. Cowan, A. W. Hunt, T. W. Phillips, S. C. Wilks, M., D. Perry, W. Fountasin, S. Hatchet, J. Johnson, M. H. Key, T. Parnell, D. M. Pennington, R. A. Snavely, Y. Takahashi, "Photonuclear Fission from High Energy Electrons from Ultraintense LaserSolid Interations," Phys. Rev. Lett. 84. 903 (2000) UCRL-JC-138297 
P3. T. E. Cowan, M. D. Perry, M. H, Key, R. R. Ditmire, S. P. Hatchett, E. A. Henry, J. D. Moody, M. J. Moran, D. M. Pennington T. W. Phillisp, T. C. Sangster, J. A. Sefcik, M. S. Singh, R. A. Snavely, M. A. Stoyer, S. C. Wilks, P.E. Yount, Y. Takahashi, B. Dong, W. Foutain, "High Energy Electrons, Nuclear Phenomena and Heating in Petawatt Laser-Solid Experiments," Lasers and Particle Beams 17, p773 (1999) UCRL-JC-133031

P4. S. P. Hatchett, C. G. Brown, T. E. Cowan, E. A. Henry, J. S. Hohnson, M. H. Key, J. A. Koch, A. B. Longdon, B. F. Lasinski, R. W. Lee, A. J. Mackinnon, D. M. Pennington, M. D. Perry, T. W. Phillips, M. Roth, T. C. Sangter, M. S. Singh, R. A. Snavely, M. A. Stoyer, S. C. Wilks, K. Yasuike, "Electron Photon and Ion Beams from the Relativistic Interaction of Petawatt Laser Pulses with Solid Target," Phys. Plasmas 5, p2076, (2000) UCRL-JC-135029

P5. M. H. Key, E. M. Campbell, Dick Lee, M. Singh, T. Cowan, A. MacKinnon, R. Snavely. B. Hammel, J. Moody, M. Stoyer, S. Hatchett, M. Moran, M. Tabak, E. Henry, A. Offenberger, D. Thompson, J. Kilkenny, M. Perry, M. Tsukamoto, J. Koch, D. Pennington, K. Wharton, B. Langdon, T. Phillips,S. Wilks, B. Lasinski, M. Roth, K. Yasuike, C. Sangster, "Progress in Fast Ignitor Research with the Nova Petawatt Laser Facility,"IAEA, Fusion Energy 1998, Vol. 3, p1093 UCRL-JI-132178

P6. M. H. Key, E.M. Campbell, T. E. Cowan, S. P. Hatchett, E. A. Henry, J. A. Koch, A. B. Langdon, B. F. Lasinski, R. W. Lee, A Mackinnon, A. A. Offenberger, D. M. Pennington, M. D. Perry, T. J. Phillips, M. Roth, T. C. Sangster, M. S. Singh, R. Sanvely, M. A. Stoye, S. C. Wilks, K. Yasuike, "Studies of the Relativistic Electron Source and Related Phenomena in Petawatt Laser Matter Interactions," published in Inertial Fusion Sciences and Applications 99, Christine Labaune, William J. Hogan, and Kazuo A. Tanaka,Editors, publ. Elsevier, p392 (1999), UCRL-VG-135477REV1

P7. M. H. Key, "The Scientific Benefits of Inertially Confined Fusion Research," Lawrence Livermore National Laboratory Report, (1999) and http://library.llnl.gov UCRL-ID-134026

P8. J. Koch, C. Brown, S. Hatchett, M. Key, R. Lee, R. Stephens, D. Pennington, and K Yasuike, "Measurements of Deep Heating Generated by Ultra-Intense Laser Plasma Interactions," published in Inertial Fusion Sciences and Applications 99, Christine Labaune, William J. Hogan, and Kazuo A. Tanaka,Editors, publ. Elsevier,Proceedings, p463 (1999) UCRL-JC-133686 
P9. J. A. Koch, S. P. Hatchett, M. H. Key, R. W. Lee, D. Pennington, R. B. Stephens, "Observation and Deep Directional Heating at Near Solid Density Caused by Laser Relativistic Electrons,” submitted to Phys. Rev. Lett. UCRL-JC-135139,

P10. B. F. Lasinski, A. B. Langdon, S. P. Hatchett, M. H. Key and M. Tabak, "PIC Simulations of Ultra Intense Laser Pulses Propagating Through Over Dense Plasma for Fast Ignitor and Radiography Applications," Phys. Plasmas 6, p2041 (1999) UCRL-JC131245

P11. A. MacKinnon, C. Brown, T. Cowan, T. Ditmire, S. Hatchett, E. Henry, M. Key, J. Koch, B. Lasinski, B. Langdon, J. Moody, D. Pennington, M. Perry, T. Phillips, M. Roth, C. Sangster, R. Snavely, M. Stoyer, M. Singh, K. Yasuike, S. Wilks, A. Offenberger, "Study of the Interaction of the Petawatt Laser Pulse with Solid Targets," Bull. Am Phys. Soc. 44, p319 (2000), UCRL-JC-135494

P12. M.D. Perry et al., "Hard X-Ray Production from High Intensity Laser Solid Interactions," Rev. Sci. Instrum. 70, p265 (1999) UCRL-JC-130942

P13. T. W. Phillips, M. D. Cable, T. E. Cowan, S. P. Hatchett, E.A. Henry, M. H. Key, M. D. Perry, T. C. Sangster, M. A. Stoyer, "Diagnosing Hot Electron Production by Short Pulse, High Intensity Lasers Using Photonuclear Reactions," Rev. Sci. Instrum. 70, p1213 (1999) UCRL-JC-129813

P14. M. Roth, T. Cowan, A. Hunt, J. Johnson, C. Brown, W. Fountain, S. Hatchett, E. Henry, J. Johnson, M. Key, T. Kuehl, T. Parnell, D. Pennington, M. Perry, T. Sangster, M. Singh, R. Snavely, M. Stoyer, Y. Takahashi, and S. Wilks, "Laser-Driven Nuclear Fusion, Positron Creation and Electron Acceleration in Ultra-Intense Laser-Solid Experiments on the Petawatt," published in the First Inertial Fusion Sciences and Applications 99, Christine Labaune, William J. Hogan, and Kazuo A. Tanaka, p1010 (1999)

P15. R.A. Snavely, S.P. Hatchett et al., "Intense Proton and Ion Beams from Petawatt Laser Experiments,” Bull. Am. Phys. Soc. 44, p229 (1999) UCRL-JC-134957 
P16. R. A. Snavely, M. H. Key, S. P. Hatchett, T. E. Cowan, M. Roth, T. W. Phillips, M. A. Stoyer, E. A. Henry, T. C. Sangster, M. S. Singh, S. C. Wilks, A. MacKinnon, A.

Offenberger, D. M. Pennington, K. Yasuike, A. B. Landon, B. F. Lasinski, J. Johnson, M. D. Perry, and E. M. Campbell, "Intense High Energy Proton Beams from Petawatt Laser Irradiation of Solids," Phys Rev. Lett., (in press) UCRL-JC-137050

P17. R. B. Stephens, M. Key, W. Meier, R. Moir and M. Tabak, "The Case for Fast Ignition as an IFE Concept Exploration Program," 1999 Fusion Summer Study Conf. (1999) UCRL-MI-135800

P18. R.B. Stephens, General Atomics, M. H. Key, J. Koch, and D. Pennington, "X-ray Imaging to Characterize MeV Electrons Propagation through Plastic Targets," published in the First Inertial Fusion Sciences and Applications 99, Christine Labaune, William J. Hogan, and Kazuo A. Tanaka, Editors, publ. Elsevier, p480 (1999) UCRL-VG-135478

P19. M. A. Stoyer, T. C. Sangster, E. A. Henry, M. D. Cable, T. E. Cowan, S. P. Hatchett, M. H. Key, M. J. Moran, D. M. Pennington, M. D. Perry, T. W. Phillips, M. S. Singh, R. A. Snavely, M. Tabak, and S. C. Wilks, "Nuclear Diagnostics for Petawatt Experiments," (in press) Sci. Instr. (2000) UCRL-JC-138297

P20. K. Walter, "The Amazing Power of the Petawatt," Science and Technology Review, publ. By LLNL, p4, March 2000 UCRL-52000-00-3

P21 S. W. Wilks, A. B. Langdon, T. E. Cowan, M. Roth, M. Singh, S. Hatchett, M. Key, D. Pennington, A. Mackinnon, and R Snavely, "Energetic Proton Generation in UltraIntense Laser-solid Interactions,"(in press) Phys. Plasmas (2000) UCRL-ID-137814

\section{Viewgraph presentations}

V1. S.P. Hatchett et al., "Ion Beams and Relativistic Electron Emissions from Petawatt Laser Pulses," Proc. of the 29th Annual Anomalous Absorption Conf., Monterey, California (1999) UCRL-JC-133725

V2. M. H. Key, E. M. Campbell, D. Lee, M. Singh, T. Cowan, A. MacKinnon, R. Snavely, B. Hammel, J. Moody, M. Stoyer, S. Hatchett, M. Moran, M. Tabak, E. Henry, A. Offenberger, D. Thompson, J. Kilkenny, M. Perry, M. Tsukamoto, J. Koch, D. Pennington, K. Wharton, B. Langdon, T. Phillips, S. Wilks, B. Lasinski, M. Roth, K. Yasuike, C. Sangster, "Laser Interaction with Matter in the Relativistic Regime," plenary 
paper at the National Conference on the Physics of Matter, Catania, Italy, June 14 - 18, 1999 UCRL-MI-134494

V3. M. H. Key, M. H. Key, E.M. Campbell, T. E. Cowan, S. P. Hatchett, E. A. Henry, J. A. Koch, A. B. Langdon, B. F. Lasinski, R. W. Lee, A Mackinnon, A. A. Offenberger, D. M. Pennington, M. D. Perry, T. J. Phillips, M. Roth, T. C. Sangster, M. S. Singh, R. Sanvely, M. A. Stoye, S. C. Wilks, K. Yasuike, "Studies of the Relativistic Electron Source and Related Phenomena in Petawatt Laser Matter Interactions," viewgraph presentation at the First International Conference on Inertial Fusion Sciences and Applications, Bordeaux, France Sept. 12 - 17, 1999 UCRL-VG-135477

V4. M.H. Key, E. M. Campbell, D. Lee, Mike Singh, T. Cowan, A. MacKinnon, R. Snavely. B. Hammel, J. Moody, M. Stoyer, S. Hatchett, M. Moran, M. Tabak, E. Henry, A. Offenberger, D. Thompson, J. Kilkenny, M. Perry, M. Tsukamoto, J. Koch, D. Pennington, K. Wharton, B. Langdon, T. Phillips, S. Wilks, B. Lasinski, M. Roth, K. Yasuike, C. Sangster, "Petawatt Laser Interactions with Matter," Seminar presentation CEA, Bruyeres le Chatel, France, June 21, 1999 UCRL-MI-134492

V5. M. H.. Key, E. M. Campbell, D. Lee, M. Singh, T. Cowan, A. MacKinnon, R. Snavely, B. Hammel, J. Moody, M. Stoyer, S. Hatchett, M. Moran, M. Tabak, E. Henry, A. Offenberger, D. Thompson, J. Kilkenny, M. Perry, M. Tsukamoto, J. Koch, D. Pennington, K. Wharton, B. Langdon, T. Phillips, S. Wilks, B. Lasinski, M. Roth, K. Yasuike, C. Sangster, " Overview of Petawatt Experiments," US-Japan Workshop on the Fast Ignitor and Related High Intensity Laser-Plasma Interactions, June $10-11,1999$ UCRL-MI-134493

V6. J. A. Koch, S. P. Hatchett et al., "Experimental Measurements of Deep Directional Heating at Near-Solid Density Caused by Laser-Generated Relativistic Electrons," Bull. Am. Phys. Soc. 44, p314 (1999) UCRL-JC-135064-ABS

V7. M.H. Key, E.M. Campbell, T. E. Cowan, S. P. Hatchett, E. A. Henry, J. A. Koch, A. B. Langdon, B. F. Lasinski, R. W. Lee, A Mackinnon, A. A. Offenberger, D. M. Pennington, M. D. Perry, T. J. Phillips, M. Roth, T. C. Sangster, M. S. Singh, R. Sanvely, M. A. Stoye, S. C. Wilks, K. Yasuike, "New Phenomena and Potential Applications at the Frontier of Extremely High Intensities," key note address at the HighPower Laser Ablation 2000, Santa Fe, NM, April 23-28, 2000 UCRL-VG-138653 
V8. M. H. Key, E.M. Campbell, T. E. Cowan, S. P. Hatchett, E. A. Henry, J. A. Koch, A. B. Langdon, B. F. Lasinski, R. W. Lee, A Mackinnon, A. A. Offenberger, D. M. Pennington, M. D. Perry, T. J. Phillips, M. Roth, T. C. Sangster, M. S. Singh, R. Sanvely, M. A. Stoye, S. C. Wilks, K. Yasuike, "Prospects for Fast Ignition Using a Petawatt Laser Facility," invited paper at the ALPHA'99 Conference, Osaka, Japan November 1-5, 1999 UCRL-VG-136219 